\title{
Antioxidant Status in Acute Stroke Patients and Patients at Stroke Risk
}

\author{
C. Zimmermann ${ }^{a} \quad$ K. Winnefeld ${ }^{b} \quad$ S. Streck ${ }^{b} \quad$ M. Roskos ${ }^{b} \quad$ R.L. Haberl ${ }^{a}$ \\ a Department of Neurology, Krankenhaus Munich-Harlaching, LMU Munich, Munich, and bepartment of \\ Clinical Chemistry and Laboratory Analysis, University Clinic Jena, FSU Jena, Jena, Germany
}

\section{Key Words}

Acute stroke $\cdot$ Stroke risk - Antioxidants $\cdot$ Superoxide dismutase · Glutathione - Glutathione peroxidase

\begin{abstract}
Background and Purpose: Antioxidant enzymes like copper/zinc superoxide dismutase (SOD), catalase and gluthatione peroxidase (GSHPx) are part of intracellular protection mechanisms to overcome oxidative stress and are known to be activated in vascular diseases and acute stroke. We investigated the differences of antioxidant capacity in acute stroke and stroke risk patients to elucidate whether the differences are a result of chronic low availability in arteriosclerosis and stroke risk or due to changes during acute infarction. Methods: Antioxidant enzymes were examined in 11 patients within the first hours and days after acute ischemic stroke and compared to risk- and age-matched patients with a history of stroke in the past 12 months ( $n=17$ ). Antioxidant profile was determined by measurement of glutathione (GSH), malondialdehyde (MDA), SOD, GSHPx and minerals known to be involved in antioxidant enzyme activation like selenium, iron, copper and zinc. Results: In comparison to stroke risk patients, patients with acute ischemic stroke had significant changes of the GSH system during the first hours and days after the event: GSH was significantly elevated in the first hours $(p<0.01)$ and GSHPx
\end{abstract}

was elevated 1 day after the acute stroke $(p<0.05)$. Selenium, a cofactor of GSHPx, was decreased ( $p<0.01$ ). GSHPx levels were negatively correlated with National Institutes of Health Stroke Scale (NIHSS) scores on admission $(r=-0.84, p<0.001)$ and NIHSS scores after 7 days $(r=-0.63, p<0.05)$. MDA levels showed a trend for elevation in the first $6 \mathrm{~h}$ after the acute stroke $(p=0.07)$. No significant differences of SOD, iron, copper nor zinc levels could be identified. Conclusions: Differences of antioxidant capacity were found for the GSH system with elevation of GSH and GSHPx after acute stroke, but not for other markers. The findings support the hypothesis that changes of antioxidant capacity are part of acute adaptive mechanisms during acute stroke.

Copyright $@ 2004$ S. Karger AG, Base

Free radicals and reactive oxygen species (ROS) are believed to cause biological cell damage. A sensitive balance between generation and neutralization of oxidants by different intra- and extracellular defense mechanisms helps to protect vital cell components. Circulating scavenging antioxidants with a high redox potential like ascorbic acid, tocopherols, $\beta$-carotene and ubiquinone, intrinsic antioxidants like bilirubin, urate and albumin as well as intracellular antioxidant enzymes like gluthatione peroxidase (GSHPx), superoxide dismutase (SOD) and catalase maintain this equilibrium.

\begin{tabular}{ll}
\hline KARGER & $\begin{array}{l}\text { () 2004 S. Karger AG, Basel } \\
0014-3022 / 04 / 0513-0157 \$ 21.00 / 0\end{array}$ \\
$\begin{array}{l}\text { Fax +4161306 12 34 } \\
\text { E-Mail karger@karger.ch } \\
\text { www.karger.com }\end{array}$ & $\begin{array}{l}\text { Accessible online at: } \\
\text { www.karger.com/ene }\end{array}$
\end{tabular}

Roman Haberl, MD

Department of Neurology

Krankenhaus Munich-Harlaching, Sanatoriumsplatz 2

DE-81545 Munich (Germany)

Tel. +498962102258, Fax +498962102453, E-Mail r.haberl@khmh.de 
Arteriosclerotic vascular damage is believed to be one of the consequences of increased oxidative stress including excessive generation of ROS, oxidation of lipoproteins and formation of arteriosclerotic plaques. Oxidative stress is also one of the mechanisms involved in neuronal damage induced by ischemia/reperfusion $[1,2]$. The antioxidant activity of plasma may be an important factor providing protection from neurological damage caused by strokeassociated oxidative stress [3, 4]. Acute ischemia leads to increased production of free radicals and ROS in tissue and plasma [1]. During the early phase of ischemia and reperfusion, antioxidants can be mobilized, though antioxidant capacity might be limited by chronically low availability, consumption of neutralizing scavenging antioxidants or excessive oxidative stress [3,5]. This study was designed to examine the differences and changes of antioxidant enzymes in acute stroke to elucidate whether there are acute adaptive changes to overcome oxidative stress.

\section{Subjects and Methods}

\section{Patient Selection}

Antioxidant markers were examined in two groups of patients: (a) in patients within the first hours and days after acute stroke (group A, n = 11) and (b) in age- and risk-matched patients with a history of stroke in the past 12 months (group B, n = 17). Group A consisted of 11 patients with symptoms of acute stroke admitted within $6 \mathrm{~h}$ after onset of neurologic deficit to the emergency room of Krankenhaus Munich-Harlaching. Blood was taken within $6 \mathrm{~h}$ after onset of symptoms and cranial CT scan was performed to exclude intracranial hemorrhage and to determine the size of infarction. Patients also had blood controls 1, 3 and 7 days after acute stroke. Neurologic examination was recorded by the National Institutes of Health Stroke Scale (NIHSS) [6] on admission and day 7 and a numeric risk score was calculated according to the Copenhagen City Heart Study (CCHS) risk score for stroke risk patients [7]. Type and etiology of infarction were determined by examination results of cranial CT, duplex ultrasonography, ECG, echocardiography and clinical situation.

Group B consisted of 17 age- and risk-matched patients with similar cardiovascular risk factors having suffered from minor stroke in the past 12 months and presenting at the outpatient clinic for checkup visits. None of the patients was suffering from another inflammatory, degenerative or malignant disease. All patients gave their written informed consent. They underwent neurological examination, cardiovascular risk factors were checked by patient history and clinical parameters, and CCHS risk score was calculated.

\section{Analysis of Blood Samples}

Venous blood samples were taken, serum and whole EDTA blood was frozen immediately and stored at $-70^{\circ} \mathrm{C}$ for a maximum of 6 months until determination of antioxidant enzymes (GSHPx, SOD), markers of peroxidation [malondialdehyde (MDA), glutathione $(\mathrm{GSH})]$ and minerals (selenium, copper, zinc, iron) involved in the regulation of antioxidant enzymes.
Serum GSHPx was determined by the method described by Paglia and Valentine [8] coupling the peroxidase reaction with the reduction of oxidized GSH reductase and NADPH. Whole blood SOD activity was measured from lysate by a chemiluminometric method using the RanSOD 125 kit (Randox Laboratories, UK ) and serum MDA was determined by condensation with thiobarbituric acid and photometric determination of the pink chromogen [9]. Whole blood GSH was measured by fluometric reaction with Ellmanns reagent described by Mergel et al. [10]. For determination of minerals, flame and flameless atomic absorption spectroscopy was used.

Normal values were based on laboratory reference values including 101 healthy subjects analyzed under the same conditions (20 female, $81 \mathrm{male}$ ). Normal values were 1.6-2.4 $\mu \mathrm{mol} / \mathrm{l}$ for MDA, 68 $97 \mu \mathrm{mol} / \mathrm{l}$ for GSH, $96-150 \mathrm{U} / 1$ for GSHPx, 15-22 U/ $\mu \mathrm{mol}$ hemoglobin for SOD, $0.72-1.33 \mu \mathrm{mol} / 1$ for selenium in serum, 9-26 $\mu \mathrm{mol} / \mathrm{l}$ for copper, $62-102 \mu \mathrm{mol} / 1$ for zinc and 51.7-95.7 $\mu \mathrm{mol} / 1$ for iron in whole blood [11].

Results are expressed as means \pm SD. For statistical analysis, the Mann-Whitney U test and Spearman rank correlation coefficient were used. A value of $p<0.05$ was considered significant.

\section{Results}

A description of the patients and their risk profile is presented in table 1 . In patients with acute stroke, MDA levels showed a trend for elevation in the first $6 \mathrm{~h}$ after stroke $(2.1 \pm 0.6 \mu \mathrm{mol} / 1, \mathrm{p}=0.07)$, which decreased to 1.7 $\pm 0.2 \mu \mathrm{mol} / 1$ after 7 days similar to the levels of stroke risk patients $(1.7 \pm 0.5 \mu \mathrm{mol} / \mathrm{l}$, table 2$)$. In more than half of the patients of group B, GSH levels were below the normal range. Compared to them, patients with acute stroke showed significantly elevated GSH levels on admission $(p<0.01$, table 2$)$.

Levels of GSHPx were elevated during the first days after acute stroke as well, showing significant elevation 1 day after the acute event (table 2, $p<0.05$ ). GSHPx levels during the first $6 \mathrm{~h}$ after acute stroke were negatively correlated with the NIHSS score on admission $(r=-0.84, p<$ $0.001)$ and the NIHSS score after 7 days $(r=-0.63, p<$ 0.05 , fig. 1).

Selenium in serum, known to be a cofactor for GSHPx, was significantly lower in acute stroke compared to stroke risk patients $(\mathrm{p}<0.05$, table 2$)$.

Whole blood SOD activity was similar in both groups of patients (table 2). There were no differences of copper or zinc - cofactors of SOD - between the groups (copper: $13.7 \pm 1.4 \mu \mathrm{mol} / \mathrm{l}$ versus $14.0 \pm 1.7 \mu \mathrm{mol} / 1$; zinc: $90 \pm 11$ versus $89 \pm 12 \mu \mathrm{mol} / 1)$. No difference in whole blood iron was found. 
Table 1. Patient data and risk profile

\begin{tabular}{|c|c|c|}
\hline & Patients with acute stroke & Patients with history of stroke \\
\hline Patients & 11 & 17 \\
\hline Female/male & $6 / 5$ & $3 / 14$ \\
\hline Age, years & $62.2 \pm 8.4$ & $63.4 \pm 7.8$ \\
\hline Systolic blood pressure, $\mathrm{mm} \mathrm{Hg}$ & $153 \pm 12$ & $143 \pm 20$ \\
\hline Diastolic blood pressure, $\mathrm{mm} \mathrm{Hg}$ & $87 \pm 7$ & $81 \pm 10$ \\
\hline CCHS stroke risk score ${ }^{1}$ & $15.7 \pm 9.4(8-38)$ & $16.1 \pm 7.9(3-30)$ \\
\hline NIHSS score on admission & $7.6 \pm 6.6(0-20)$ & \\
\hline NIHSS score on day 7 & $3.9 \pm 5.3(0-18)$ & \\
\hline Type of ischemia & $\begin{array}{l}\text { PRIND/TIA: } 7 \text { pat. (64) } \\
\text { stroke: } 4 \text { pat. }(36)\end{array}$ & $\begin{array}{l}\text { PRIND/TIA: } 11 \text { pat. }(65) \\
\text { stroke: } 6 \text { pat. }(35)\end{array}$ \\
\hline Size of infarction & $\begin{array}{l}4 \text { pat.: } \text { small lesion }^{2}(36) \\
3 \text { pat.: } \text { moderate lesion }^{3}(27) \\
4 \text { pat.: large lesion }{ }^{4}(36)\end{array}$ & not available \\
\hline Type of infarction & $\begin{array}{l}4 \text { atherothrombotic }(36) \\
3 \text { cardioembolic }(27) \\
4 \text { microangiopathic }(36)\end{array}$ & $\begin{array}{l}9 \text { atherothrombotic (53) } \\
4 \text { cardioembolic }(24) \\
4 \text { microangiopathic }(24)\end{array}$ \\
\hline Stroke prevention & $\begin{array}{l}5 \text { pat.: ASS }(45) \\
2 \text { pat.: clopidogrel }(18) \\
4 \text { pat.: anticoagulation }(36)\end{array}$ & $\begin{array}{l}7 \text { pat.: ASS }(41) \\
5 \text { pat.: clopidogrel }(29) \\
5 \text { pat.: anticoagulation }(29)\end{array}$ \\
\hline 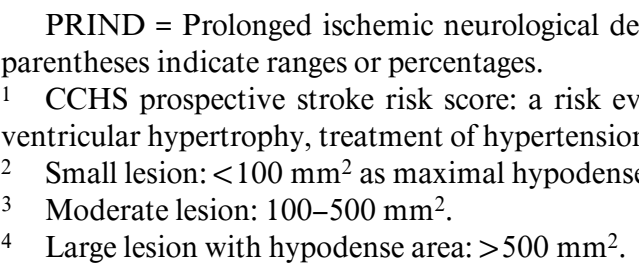 & $\begin{array}{l}\text { ficit; TIA = transient ischemi } \\
\text { aluation by age, blood press } \\
\text { n, cardiovascular disease and c } \\
\text { e area on the cranial CT scan }\end{array}$ & $\begin{array}{l}\text { tack; pat. = patients. Figures in } \\
\text { atrial fibrillation, smoking, left } \\
\text { etes mellitus. } \\
\text { the largest demarcation. }\end{array}$ \\
\hline
\end{tabular}

Table 2. Antioxidant markers in patients with acute ischemic stroke in comparison to patients with a history of stroke

\begin{tabular}{|c|c|c|c|c|c|c|}
\hline & \multirow{2}{*}{$\begin{array}{l}\text { Laboratory } \\
\text { reference } \\
\text { values }\end{array}$} & \multirow{2}{*}{$\begin{array}{l}\text { Patients with } \\
\text { a history of } \\
\text { stroke } \\
(\mathrm{n}=17)\end{array}$} & \multicolumn{4}{|c|}{ Patients with acute stroke $(\mathrm{n}=11)$} \\
\hline & & & admission & day 1 & day 3 & day 7 \\
\hline MDA i.S., $\mu \mathrm{mol} / 1$ & $1.6-2.4$ & $1.7 \pm 0.5$ & $2.1 \pm 0.6$ & $1.9 \pm 0.4$ & $1.9 \pm 0.3$ & $1.7 \pm 0.2$ \\
\hline GSHPx i.S., U/1 & $96-150$ & $113 \pm 36$ & $128 \pm 44$ & $153 \pm 37^{b}$ & $165 \pm 55^{c}$ & $147 \pm 61$ \\
\hline GSH i.B., $\mu \mathrm{mol} / 1$ & $68-97$ & $58 \pm 23$ & $84 \pm 26^{\mathrm{a}}$ & $78 \pm 39$ & $81 \pm 42$ & $77 \pm 34$ \\
\hline 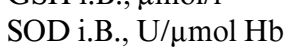 & $15-22$ & $12.2 \pm 2.1$ & $12.2 \pm 2.9$ & $12.7 \pm 4.3$ & $10.7 \pm 1.2$ & $12.8 \pm 2.6$ \\
\hline Se i.S., $\mu \mathrm{mol} / 1$ & $0.72-1.33$ & $0.93 \pm 0.14$ & $0.78 \pm 0.12^{\mathrm{a}}$ & $0.78 \pm 0.14$ & $0.77 \pm 0.16$ & $0.82 \pm 0.13$ \\
\hline $\mathrm{Fe}$ i.B., $\mu \mathrm{mol} / 1$ & $52-96$ & $73 \pm 9$ & $66 \pm 13$ & $73 \pm 12$ & $69 \pm 13$ & $72 \pm 9$ \\
\hline
\end{tabular}

i.S. = In serum; i.B. $=$ in whole blood/lysate.

${ }^{\mathrm{a}} \mathrm{p}<0.01$ compared to patients at stroke risk, ${ }^{\mathrm{b}} \mathrm{p}<0.05$ compared to patients at stroke risk, ${ }^{\mathrm{c}} \mathrm{p}=0.07$ compared to patients at stroke risk. Laboratory reference values have been established before from 101 healthy subjects. 


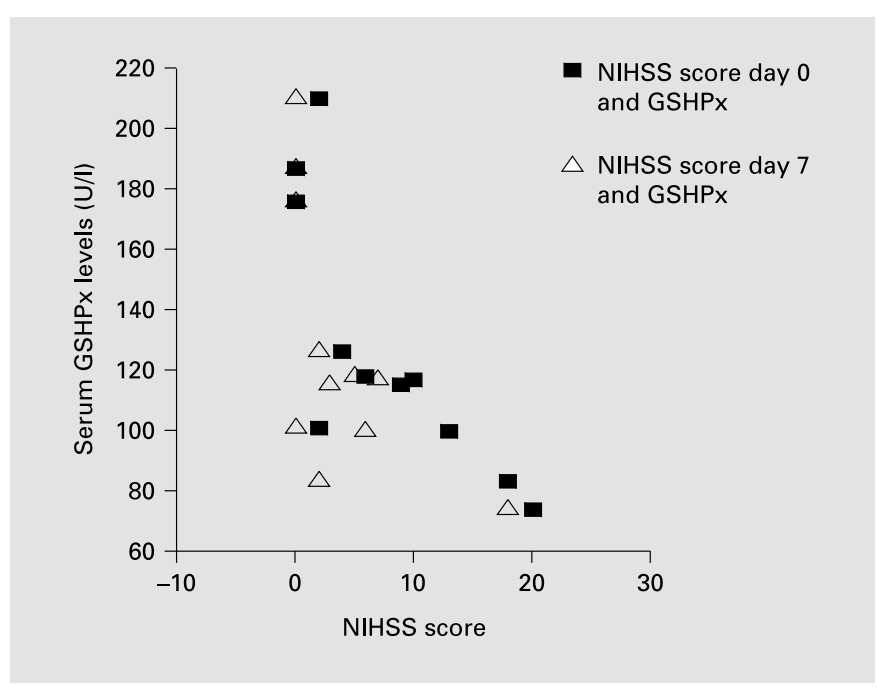

Fig. 1. Negative correlation of the NIHSS score and serum GSHPx levels on day $0(\mathrm{r}=-0.84, \mathrm{p}<0.001)$ and day $7(\mathrm{r}=-0.63, \mathrm{p}<0.05)$.

\section{Discussion}

We could identify some differences of antioxidant markers and enzymes between patients with acute stroke in comparison to age- and risk-matched patients with a history of ischemic stroke: most significant differences could be found for the GSH system, while MDA levels showed only a trend for elevation in the first hours after acute stroke.

The role of endogenous defense mechanisms including antioxidant enzymes in stroke risk and arteriosclerosis is controversial [3]. On the one hand, decreased availability of antioxidant defense mechanisms is a chronic problem in arteriosclerosis. On the other hand, the amount of oxidative stress and acute changes of antioxidant capacity might influence the prognosis of cerebral ischemia [2].

MDA levels are widely accepted as markers of lipid peroxidation in states of increased oxidative stress. Some but not all authors have found increased MDA levels after acute stroke [12-14]. Our patients with acute stroke showed a trend for MDA elevation during the first hours after the event decreasing to levels similar to those of stroke risk patients after 7 days.

GSH is part of the intracellular nonenzymatic smallmolecule antioxidant defense system. It is a free radical scavenger and a proton donor for GSHPx and known to play a neuroprotective role $[15,16]$. Depleted GSH levels have been found in a number of neurodegenerative diseases with states of oxidative stress as well as in the pro- cess of normal aging [15]. Nearly two thirds of our patients with a stroke in the past showed decreased GSH levels, possibly associated with increased oxidative stress and arteriosclerosis. In animal models, acute increase in GSH by activation of GSH synthase has been found during acute oxidative stress [17]. Our patients had elevated GSH levels during the first hours after acute stroke. This could be part of a first-line defense mechanism against oxidative stress, providing neuroprotection against amino acid excitotoxicity in stroke [16].

Changes in enzymatic antioxidative defense mechanisms after acute stroke are controversial. Some authors found reduced SOD activity in red blood cells and serum of patients with acute stroke [5, 13]. Reduced SOD levels led to an enhancement and progression of cerebral infarctions $[5,18]$. Others have found increased levels of SOD in red blood cells after cerebrovascular events [19]. We did not find any significant differences of erythrocyte SOD activity or its cofactors copper and zinc between the two groups and there was no correlation between erythrocyte SOD activity and infarct size or NIHSS score in our patients. Anyhow, the patient number might be too small to draw negative conclusions and infarctions might not have been large enough to have obvious influence on whole blood SOD levels.

In our study, acute stroke was associated with increased serum levels of GSHPx during the first and third day after the acute event compared to patients with a history of stroke. Zachara et al. [20] found increased plasma GSHPx levels up to $48 \mathrm{~h}$ after myocardial infarction and Cherubini et al. [18] a significant increase in plasma GSHPx activity between day 1 and 6 after acute stroke. On the other hand, autopsied human brain tissue was GSHPx positive only 6 days after acute stroke [21] and red blood cell GSHPx activity even decreased in patients with acute ischemic stroke [13]. Differences could be explained by the fact that plasma GSHPx mainly originates from hepatocytes [22], while glial cells were found to be the major source of brain GSHPx [21].

Several animal studies have found that GSHPx has protective effects on brain damage and that reduced GSHPx levels are associated with an increased stroke risk $[23,24]$. Data from our patients at stroke risk fit this concept, showing that high GSHPx levels correlated with low neurologic deficit (low NIHSS score on admission) as well as good outcome (low NIHSS score on day 7).

Selenium was the only mineral found to be decreased in acute stroke patients in our study. Acute decrease in selenium levels in serum are associated with acute inflammatory processes [25]. Bor et al. [26] found decreased 
selenium levels after acute myocardial infarction. Levels of our stroke risk patients were in the normal range, while levels were decreased after acute stoke. We can only speculate that this is due to acute inflammatory processes after stroke.

There are limitations of our study and the number of examined patients is small. Only 4 of the 11 patients with acute infarction developed severe stroke and large cerebral ischemic lesion; most of the patients only had minor or no permanent deficit. This might explain why we could only find small changes of the antioxidant system. However, we could show that there are differences of the antioxidant status between patients at stroke risk and patients with acute stroke. Our data support the hypothesis that in acute stroke, activation of the GSH system helps to overcome oxidative stress. It is possible that anti- platelet drugs might have influenced the antioxidant systems as well. However, the use of stroke prevention drugs was similar in both groups and all stroke patients were treated with either ASS, clopidogrel or anticoagulation after exclusion of intracerebral hemorrhage. Nevertheless, further studies are needed to find out whether antioxidant changes will have prognostic and therapeutic implications for stroke and stroke risk patients.

\section{Acknowledgements}

The study was supported by a fund from the German Bundesministerium für Bildung und Forschung (BMBF) Kompetenznetz Schlaganfall, Project A6. Special thanks are to Dr. Wanner, Laboratory of Clinical Chemistry, Krankenhaus München-Harlaching for cooperation and technical analysis of laboratory tests.

\section{References}

1 Carden DL, Granger DN: Pathophysiology of ischaemia-reperfusion injury. J Pathol 2000; 190:255-266.

2 Chan PH: Role of oxidants in ischemic brain damage. Stroke 1996;27:1124-1129.

3 El Kossi MM, Zakhary MM: Oxidative stress in the context of acute cerebrovascular stroke. Stroke 2000;31:1889-1892.

4 Leinonen JS, Ahonen JP, Lonnrot K, Jehkonen M, Dastidar P, Molnar G, Alho H: Low plasma antioxidant activity is associated with high lesion volume and neurological impairment in stroke. Stroke 2000;31:33-39.

5 Spranger M, Krempien S, Schwab S, Donneberg S, Hacke W: Superoxide dismutase activity in serum of patients with acute cerebral ischemic injury. Correlation with clinical course and infarct size. Stroke 1997;28:2425-2428.

6 Goldstein LB, Samsa GP: Reliability of the National Institutes of Health Stroke Scale. Extension to non-neurologists in the context of a clinical trial. Stroke 1997;28:307-310.

7 Truelsen T, Lindenstrom E, Boysen G: Comparison of probability of stroke between the Copenhagen City Heart Study and the Framingham Study. Stroke 1994;25:802-807.

8 Paglia DE, Valentine WN: Studies on the quantitative and qualitative characterization of erythrocyte glutathione peroxidase. J Lab Clin Med 1967;70:158-169.

9 Yagi K: Lipid peroxides and human diseases. Chem Phys Lipids 1987;45:337-351.

10 Mergel D, Andermann G, Andermann C: Simultaneous spectrophotometric determination of oxidized and reduced glutathione in human and rabbit red cells. Methods Find Exp Clin Pharmacol 1979;1:277-283.

Antioxidant Status in Acute Stroke Patients and Patients at Stroke Risk
11 Winnefeld K, Streck S, Treff E, Jutte H, Kroll E, Marx H: Reference ranges of antioxidant parameters in whole blood (erythrocytes) in a Thuringa region. Med Klin 1999;94(suppl 3):101-102.

12 Chang CY, Lai YC, Cheng TJ, Lau MT, Hu ML: Plasma levels of antioxidant vitamins, selenium, total sulfhydryl groups and oxidative products in ischemic-stroke patients as compared to matched controls in Taiwan. Free Radic Res 1998;28:15-24.

13 Demirkaya S, Topcuoglu MA, Aydin A, Ulas UH, Isimer AI, Vural O: Malondialdehyde, glutathione peroxidase and superoxide dismutase in peripheral blood erythrocytes of patients with acute cerebral ischemia. Eur J Neurol 2001;8:43-51.

14 Sharpe PC, Mulholland C, Trinick T: Ascorbate and malondialdehyde in stroke patients. Ir J Med Sci 1994;163:488-491.

15 Schulz JB, Lindenau J, Seyfried J, Dichgans J: Glutathione, oxidative stress and neurodegeneration. Eur J Biochem 2000;267:4904-4911.

16 Bains JS, Shaw CA: Neurodegenerative disorders in humans: The role of glutathione in oxidative stress-mediated neuronal death. Brain Res Brain Res Rev 1997, 25:335-358

17 Chang ML, Klaidman LK, Adams JD: The effects of oxidative stress on in vivo brain GSH turnover in young and mature mice. Mol Chem Neuropathol 1997;30:187-197.

18 Cherubini A, Polidori MC, Bregnocchi M, Pezzuto S, Cecchetti R, Ingegni T, di Iorio A, Senin U, Mecocci P: Antioxidant profile and early outcome in stroke patients. Stroke 2000;31: 2295-2300.

19 Kocaturk PA, Akbostanci MC, Isikay C, Ocal A, Tuncel D, Kavas GO, Mutluer N: Antioxidant status in cerebrovascular accident. Biol Trace Elem Res 2001;80:115-124.
20 Zachara BA, Ukleja-Adamowicz M, Nartowicz E, Lecka J: Increased plasma glutathione peroxidase activity in patients with acute myocardial infarction. Med Sci Monit 2001;7:415420.

21 Takizawa S, Matsushima K, Shinohara Y, Ogawa $\mathrm{S}$, Komatsu N, Utsunomiya $\mathrm{H}$, Watanabe $\mathrm{KJ}$ : Immunohistochemical localization of glutathione peroxidase in infarcted human brain. Neurol Sci 1994;122:66-73.

22 Avissar N, Whitin JC, Allen PZ, Wagner DD, Liegey P, Cohen HJ: Plasma selenium-dependent glutathione peroxidase. Cell of origin and secretion. J Biol Chem 1989;264:1585015855.

23 Murakami T, Takemori K, Takeda T, Yoshizumi H: Relationship between erythrocytes glutathione peroxidase and incidence of stroke lesion in the stroke-prone spontaneously hypertensive rat. Clin Exp Pharmacol Physiol Suppl 1995;1:S162-164.

24 Weisbrot-Lefkowitz M, Reuhl K, Perry B, Chan $\mathrm{PH}$, Inouye $\mathrm{M}$, Mirochnitchenko $\mathrm{O}$ : Overexpression of human glutathione peroxidase protects transgenic mice against focal cerebral ischemia/reperfusion damage. Brain Res Mol Brain Res 1998;53:333-338.

25 Maehira F, Luyo GA, Miyagi I, Oshiro M, Yamane N, Kuba M, Nakazato Y: Alterations of serum selenium concentrations in the acute phase of pathological conditions. Clin Chim Acta 2002;316:137-146.

26 Bor MV, Cevik C, Uslu I, Guneral F, Duzgun E: Selenium levels and glutathione peroxidase activities in patients with acute myocardial infarction. Acta Cardiol 1999;54:271-276. 